\title{
Basic eligibility: Threshold or fork in the road to higher education?
}

Per Andersson

\section{Linköping University Post Print}

\section{Tweet}

N.B.: When citing this work, cite the original article.

Original Publication:

Per Andersson, Basic eligibility: Threshold or fork in the road to higher education?, 2013, Journal of Adult and Continuing Education, (19), 2, 24-44.

http://dx.doi.org/10.7227/JACE.19.2.3

Copyright: Manchester University Press

http://www.manchesteruniversitypress.co.uk/

Postprint available at: Linköping University Electronic Press

http://urn.kb.se/resolve?urn=urn:nbn:se:liu:diva-100901 


\title{
Basic eligibility: Threshold or fork in the road to higher education?
}

\author{
Per Andersson \\ Linköping University \\ E-mail: per.andersson@liu.se
}

\section{Abstract}

Sweden has a two-step selection process for admission to higher education. Eligibility is assessed to ensure that the candidates have the ability to take the course/programme. Selections are made based in part on other measures. The focus here is eligibility, particularly the 25:4 scheme, a measure introduced to widen access to higher education in the 1970s but since abandoned. An age of 25 and 4 years of work experience were the main criteria of basic eligibility under this scheme. This exploratory study identifies the characteristics of 25:4 applicants and compares them to applicants with other types of eligibility and comparable groups in the population. What were the characteristics of 25:4 applicants? In what ways did they differ from other applicants and from the population in general? Results illustrate the scheme's influence, which was stronger on application patterns and weaker on the admission patterns of traditional and non-traditional applicants/students.

\section{Keywords}

eligibility; admission; higher education; non-traditional applicants

\section{Introduction}

Sweden has a long tradition of inclusiveness in its educational system. The Swedish system provides broad opportunities for both young people and adults. Various 
initiatives have been undertaken to give adults a second chance and provide opportunities for continuing education and lifelong learning. These opportunities extend to all levels of education, including higher education.

In higher education, varying initiatives have been proposed to widen the admission of what was often referred to as 'non-traditional' students. These initiatives have been successful to the extent that these students are no longer non-traditional; they are mainstream. As table 3 below shows, 55\% of these students are more than 25 years old. Thus, non-traditional students are more common than 'traditional' students (traditional in that their background predicts a direct transition from upper secondary school). This success in the widening of admissions has even been viewed as a problem, as it means that younger applicants may be forced to wait before being admitted to highdemand programmes.

Internationally there has been a debate on lifelong learning and not least the opportunities to increase adults' involvement in higher education (see, e.g., Davies, 1995; Mark, Pouget and Thomas, 2006; Osborne, 2003). Widening access is seen as a tool for inclusion as well as social and economic development. In this context, where Sweden has the tradition of inclusiveness in education, the present study will discuss a measure for inclusion which has now been abandoned, a decision that could mean reduced access for adults in Swedish higher education.

\section{The admissions system in Sweden}

The higher education admissions system in Sweden could be viewed as a two-step system of eligibility and selection. First, eligibility is assessed through varying measures that act as a threshold to ensure that the potential students have the ability to take the course or programme in question. There is a basic eligibility requirement in relation to higher education in general, and there are additional requirements of specific eligibility 
for specific courses/programmes. Second, if there are more eligible applicants than open spots, a selection process is undertaken based in part on other measures, mainly grades and a scholastic aptitude test. The focus of this paper is the first step, the question of eligibility, particularly basic eligibility. However, it also considers the results of the selection process.

There are different ways to acquire basic eligibility for higher education in Sweden. The traditional track is upper secondary school, where young people normally study from the ages of 16 to 19. There are other opportunities for adult students, which act as alternatives or supplements to 'half' an upper secondary school education. Municipal adult education provides formal education with courses equivalent to those of upper secondary school. Folk high schools are adult education institutions that provide non-formal education; their general courses of study could provide eligibility for higher education. A foreign education could also secure eligibility.

Further, it should be noted that Sweden differs from many other countries in that there is no separate provision of adult and continuing education within higher education. Everyone, independent of age, could apply for and participate in the same courses and programmes, but there are still part-time and distance courses/programmes that could be more attractive to older students.

Another factor that should be mentioned, even if it is not part of the admission system per se, is the fact that there are no student fees in Sweden, except for students from outside the EU. Thus, after admission, higher education is free for all Swedes, and there is also a system of study subsidies and loans for students to cover their costs of living. 


\section{The 25:4 scheme}

In the 1970 s, the $25: 4$ scheme (initially $25: 5$ ) was introduced as a measure to widen access to higher education by providing a different basis for eligibility. Adoption of the scheme meant that an age of 25 and 4 years of work experience were the primary criteria of this alternative track for basic eligibility. Additional criteria included having completed courses in Swedish and English at the upper secondary level. However, this scheme is no longer in use. Since a policy was put in place in July 2008, it has no longer been possible to become eligible through this route. However, it was possible for a person who had achieved 25:4 eligibility by the end of June 2008 to use it until the end of 2011.

It should also be noted that the decision to introduce and establish the 25:4 scheme was made by the left wing, and widening access was emphasised in the proposal. The goals were to promote social justice and equal opportunities and to improve higher education by fostering a higher degree of diversity among the student population (Andersson and Fejes, 2005; Ministry of Education, 1970, 1974) and 'intergenerational social mobility' (Kim, 1982). Notably, the original introduction of the idea actually came from the right wing, with a different motivation. The main argument from the right wing was work-life related, with the goal of improving opportunities for the competence development of employees through shorter work-related courses in higher education (Kim, 1982). The decision to remove the scheme was made by the present right-wing majority, as part of a policy to increase direct transition from upper secondary school and reduce the problem of reduced admission of younger applicants.

\section{Non-traditional applicants}

The definition of non-traditional applicants in this paper is partly based on age and partly on educational background. Based on the interest in the 25:4 scheme, those 
younger than 25 can, in one sense, be viewed as traditional, even if they do not make the direct transition from upper secondary school to higher education. Under this system, educational background is defined in terms of type of basic eligibility for higher education: upper secondary school is the traditional background, and formal adult education, folk high school, and 25:4 are the main types of non-traditional background. The latter definition identifies students younger than 25 as non-traditional if they do not have the traditional upper secondary school background. This somewhat ambiguous definition of non-traditional applicants is still useful for the discussions here, but it should be noted that it is not used to define a specific unified group in the statistical descriptions.

\section{Aim of the study}

Thus, the focus of this paper is the role of basic eligibility - particularly the 25:4 scheme - in the application process for higher education. The aim of the exploratory study discussed here is to identify the characteristics of the applicants in the 25:4 group and compare them with groups of applicants with other types of basic eligibility, particularly from upper secondary school and adult education. What were the characteristics of 25:4 applicants? Who were these applicants, compared to the general population? In what ways did 25:4 applicants differ from other applicants in terms of background, type of educational choice, and success in the central admission process?

\section{The 25:4 scheme and the admission system in retrospect}

Eligibility, particularly the 25:4 scheme, has not been a focus of research on admission to higher education. The implementation of the 25:4 opportunity (initially 25:5, requiring 5 years of work-life experience) in the 1970s was described and analysed by Kim (1982). She describes its outcomes in terms of admissions during the early years and the motivations behind the scheme. Kim (1982) also notes the lack of follow-up on the 
scheme, concerning, for example, 'the social and educational background of 25/5students e g their own social status when entering higher education and the proportion of "pure" 25/5s'. This lack remained evident until the study from which the present paper stems analysed the recent outcomes of the scheme. The implementation of the 25:4 scheme was also part of the 1977 admissions reform in Swedish higher education, a reform of the admissions system as a whole, which has been analysed by Kim (1983, 1998).

An analysis of the admission system in general shows that the system has acted as a sorting mechanism rather than as a threshold. That is, those who want to enter higher education generally succeed, although not necessarily on their first try or in the programme to which they first applied. Thus, there is a forking function in the system that sorts applicants/students between more or less attractive alternatives (Kim, 1998).

The selection process has been focused on more strongly than the question of eligibility. The Swedish Scholastic Aptitude Test, SweSAT (see, e.g., Wedman, 1994) is of particular interest to the background of the present study. The test was introduced in parallel to the 25:4 scheme as a selection instrument for non-traditional applicants: that is, applicants lacking the grades from upper secondary school that are generally used to secure eligibility. For example, the influence of gender and socioeconomic background on the SweSAT test results have been analysed (see, e.g., Stage, 1988, 1993, 2005). The influence is low for both variables but somewhat higher concerning gender: it works in favour of male test takers. It should be noted that there are additional differences in the area of grades from the upper secondary level, but these grade differences are in favour of female students. Another example was presented by Cliffordson and Askling (2006), who analysed the influence of different selection instruments on recruitment and achievement in medical education. Comparing grades, SweSAT, and step-wise 
procedures, they show that step-wise procedures promote study efficiency best but favour applicants with upper middle-class and Swedish backgrounds. The use of upper secondary school grades as a selection instrument promotes diversity and study efficiency, while the use of SweSAT scores diminish both study efficiency and diversity.

Berggren (2006) discusses the 'second chance' alternative paths to higher education for those who want to change their trajectories in life. These paths turn out to primarily facilitate entry for upper middle-class students, particularly men from this group. Upper middle-class students are the most successful at entering attractive programmes: one of the main explanations for this is that the women in this group are the highest achieving students and therefore they compete successfully for all types of study programmes.

When the decision was made to remove the 25:4 plan, the new method of obtaining basic eligibility outside the school system was through an individual assessment of 'real' (actual) competence: that is, whether an applicant had the necessary competence to enter higher education would be individually decided, based on claims provided by that applicant. It has been demonstrated that this new initiative is representative of a shift in discourse. In the 1950s, the idea of the 'reserve of talent/ability' was much discussed and promoted, an idea focusing on general, individual characteristics as the argument for a broader range of admission to upper secondary school and higher education. In the 1970s, the concept of the reserve of talent was instrumentalised in SweSAT, which is similar to an intelligence test. At the same time, the 25:4 scheme had a focus that was similarly broad but that focused on experiences in general, independent of their content. However, later policy initiatives concerning 'real competence' and recognition (validation) of prior learning are part of a 
discourse with a focus on specific experiences and particular competences (Andersson and Fejes, 2005).

\section{Design of the study}

Sweden has a central selection and admission system, in which the Swedish Agency for Higher Education Services (Swedish abbreviation VHS) takes care of most of the admission processes for Swedish higher education. Since 2007, the system has covered admissions for both shorter courses and longer programmes. The present analysis is based on material consisting of data from the admission rounds for courses/programmes starting in the autumn semester of 2008 , the last admission round in which new potential applicants could still qualify through the 25:4 scheme. These data include information concerning eligibility, priority between alternative courses, the institution of higher education at which the course is situated, the length of the course in terms of credit points and study pace, the form of instruction, and the result of the admission/selection process for the entire population of those who applied through the VHS system. The data were provided by VHS. They have been anonymised and made available for analysis by Statistics Sweden, which has also provided supplementary background information on the applicants. In the present study, data concerning age, gender, socioeconomic background, and foreign/Swedish background are used.

In most cases, the data have been transformed into new variables and categories useful for the present analysis. The following variables/categories are used:

* Gender. Female and male.

* Age. Applicants have been categorised in age groups based on their ages by the end of 2007.

* Socioeconomic background. The categorisation of socioeconomic background is based in the socioeconomic classifications from 1985 and 1990. The categories in 
the classification are grouped as follows, based on own and parents' education and employment: upper middle class (SOC I), lower middle class (SOC II), and working class (SOC III). In the analysis, the applicant is put in the highest social group registered for father, mother or him/herself, in 1985 and/or 1990. Those without any such registration are classified as 'not indexed'.

* Foreign/Swedish background. Here, Swedish background means that the person and at least one of the parents were born in Sweden. Foreign background includes people born abroad and people born in Sweden if both parents were born abroad.

* Eligibility. When it comes to the variable of basic eligibility, the following categories are used:

- Upper secondary school (Upsec)

- Formal adult education (AE)

- Folk high school (FHS)

- Foreign grades (Foreign)

- 25:4 eligibility (25:4)

- Other pre-education (Other) (mainly eligibility based on prior participation in courses in higher education) 
- More than one type of eligibility, including 25:4 and upper secondary school (25:4 + Upsec) (this might include more than these two alternatives)

- More than one type of eligibility, including 25:4 but not upper secondary school (25:4 + more, not Upsec)

- More than one eligibility, not including 25:4 (more than one, not 25:4)

* Type of higher education institution. The institutions are categorised as universities, prestigious institutes (in the areas of technology, economics, medicine, the arts, etc.), or university colleges.

* Length of course/programme. Courses/programmes applied to are categorised into groups based on the length in terms of credit points, where 15 credit points equals 10 weeks of full-time studies.

* Study pace. Courses/programmes are categorised based on the study pace as a percentage of full-time status.

* Teaching form. Normal or distance.

* Result of selection process. The final results of the central admission process, here for the applicant's first-priority course/programme. The categories are admitted, substitute, or rejected. Applications are rejected if, for example, the demands of special eligibility are not fulfilled. It should be noted that a local selection process takes place after the central process is complete. If there are late cancellations of applications, the local university may admit new students among the substitutes.

Some data are missing from these materials, depending on the quality of the data in different background variables. The analysis applies descriptive statistics to explore the 
data and illustrate the distribution of applicants in different categories. The study does not rely on any representative sample but is a study of a full cohort of applicants, which means that no significant rates related to sampling are calculated. However, in tables 6 to 16 it has been calculated if the distributions on different categories in sub-groups of applicants differ significantly from the distribution in the population of applicants. Values that do not differ significantly from the distribution in the population on the 5\% level have been bracketed in the tables. That is, there is a probability of at least $95 \%$ that values not bracketed differ significantly from the distribution in the population of applicants.

For the purposes of comparison, the study also includes data on comparable age groups in the Swedish population as a whole. These data come from the official statistics available through Statistics Sweden (2010). Unfortunately, there are some differences between the age groups included in data on the Swedish population $(15+$ or $16+)$, and the age of applicants (normally 19+) (see tables 1-4). However, these were the best data available in publicly published statistics, and the differences were not considered to influence the more general comparisons made in any significant way.

It should be noted that this study is based on data from official registers. This does not mean that all the data are correct. First, there are a number of internal dropouts in certain categories, but these drop-out rates are usually low, demonstrating that they have little influence on the results. Second, the register data from VHS are based on the information submitted by the applicants. For example, applicants might have a type of eligibility that is not referred to in the application and was, therefore, not included in the register data. In one case, the data concerning educational background among those registered with only 25:4 eligibility were compared to data from Statistics Sweden concerning educational background. This comparison exhibited some inconsistency, but 
it is difficult to determine the extent to which the data from VHS concerning eligibility are actually wrong, as their information is not fully comparable: see the comment on table 5, below. Nevertheless, this study is based on the existing data. In the discussions, these data are considered correct, which might reduce the quality of the results. On the other hand, no sample has been made, and the fact that a whole cohort of applicants is included with a low rate of internal drop-outs means that the results could be considered reliable to a high degree.

The choice of the autumn 2008 admission round for this study could be discussed on the basis of the fact that this was the last round when it was still possible to qualify for the 25:4 scheme. However, this is not expected to have had any significant influence on the application patterns on this specific occasion, as those who had qualified by then still had the opportunity to apply within the scheme for another three and a half years. Further, this study is part of a larger project, which also includes a follow-up survey that will be presented elsewhere, and for which applicants from this particular round was a suitable target group.

\section{Results}

The results identify the differences and similarities in the types of education and in background factors, such as the age, gender, and socioeconomic status of the applicants. The admissions results of the applications are also included in the analysis.

\section{The population of applicants in autumn 2008}

A total of 288,986 individuals applied through the VHS system for courses and study programmes beginning in autumn 2008. There are three admission rounds - spring, summer, and autumn - each year, but the autumn round is the most encompassing, as most courses and programmes start in the autumn semester. A rather high number of 
courses and programmes also start in the spring semester, while the summer semester offers a more limited number of shorter courses.

The background of the applicants in this round shows that $64 \%$ are female, and $15.8 \%$ have a foreign background, which means that there are more women and fewer people with foreign backgrounds than in the comparable national population (table 1).

Table 1. Distribution (\%) of women and men and Swedish/foreign background in the group of applicants for higher education in autumn 2008 and in the Swedish population age $15+$ in autumn 2008

\begin{tabular}{lrrrr}
\hline & Women & Men & Swedish background & Foreign background \\
\hline Applicants & 64.0 & 36.0 & 84.2 & 15.8 \\
Population 15+ & 50.6 & 49.4 & 81.9 & 18.1 \\
\hline
\end{tabular}

Note: Internal drop-out among applicants, 1.4\%

The age of the applicants (table 2) varies from 16 to 91 years. Even if the group of 1624-year-olds is the biggest, more than half of the applicants belong to the group of 25 years and older, who could potentially have the 25:4 eligibility. It should be noted that there is one person with 25:4 eligibility in the 16-24 years group; see table 9. This is a result of an age variable based on age by the end of 2007: i.e., it was possible to reach 25:4 eligibility before the autumn 2008 admission round. It should be noted that the educational background of higher education is not included in the present analysis. It is possible to study shorter courses for a longer period to obtain a degree, which means that a number of applicants are already university students, and their applications are not a matter of entering higher education but of continuing study. 
Table 2. Age distribution in population and among applicants

\begin{tabular}{cccc}
\hline & & $\begin{array}{c}\text { Total } \\
\text { population } \\
15+\end{array}$ & $\begin{array}{c}\text { Total applicants } \\
\text { autumn 2008 }\end{array}$ \\
\hline Age & $16-24$ & 15.8 & 48.9 \\
group & $25-34$ & 14.9 & 29.4 \\
& $35-44$ & 16.9 & 13.7 \\
& $45-54$ & 15.3 & 6.0 \\
$55-64$ & 15.8 & 1.6 \\
& 65 and & 21.3 & 0.4 \\
older & & \\
\cline { 2 - 3 } & Total & 100.0 & 100.0 \\
Total (N) & 7713945 & 286615 \\
Missing & & 2371 \\
\hline
\end{tabular}

However, these figures could be compared to the numbers of those who actually studied in higher education in autumn 2008 (independent of when they applied and entered) (table 3). This comparison demonstrates that there was an even higher proportion of non-traditional (here 25+) students in that group than among that year's applicants.

Table 3. Swedish population 15-64 years, participation in higher education in autumn 2008, distributions of age groups and women/men

\begin{tabular}{rrrr}
\hline \multicolumn{1}{l}{ Age group } & \% of women & \% of men & \% of all students \\
\hline $15-24$ & 42.3 & 48.9 & 44.9 \\
$25-34$ & 31.5 & 35.5 & 33.1 \\
$35-44$ & 16.1 & 9.8 & 13.6 \\
$45-54$ & 7.9 & 4.0 & 6.4 \\
$55-64$ & 2.2 & 1.7 & 2.0 \\
& 100.0 & 100.0 & 100.0 \\
& & & Men \\
\cline { 2 - 4 } & $\mathbf{N}$ & Women & All students \\
\cline { 2 - 4 } \% of all students & 197153 & 39.4 & 325469 \\
\hline
\end{tabular}

The applicants' socioeconomic backgrounds (table 4) present a distribution in which the lower and upper middle classes are over-represented among the applicants as 
compared to the population. Notably, the proportion of lower middle-class women exhibits the smallest difference between the applicants and the general population. On the other hand, those with a working-class background are under-represented, particularly the men in this group.

Table 4. Distribution (\%) of socioeconomic backgrounds (SEI 1-3) among employed 16+ members of the Swedish population and among applicants to higher education in autumn 2008: women, men, and in total

\begin{tabular}{|c|c|c|c|c|c|c|c|}
\hline & & $\begin{array}{c}\text { Population } \\
\text { women } 16+ \\
\text { employed } \\
\text { FOB90 }\end{array}$ & $\begin{array}{l}\text { Population } \\
\text { men } 16+ \\
\text { employed } \\
\text { FOB90 }\end{array}$ & $\begin{array}{c}\text { Population } \\
16+ \\
\text { employed } \\
\text { FOB90 }\end{array}$ & $\begin{array}{l}\text { Applicants } \\
\text { autumn } \\
2008 \\
\text { women }\end{array}$ & $\begin{array}{l}\text { Applicants } \\
\text { autumn } \\
2008 \text { men }\end{array}$ & $\begin{array}{l}\text { Total } \\
\text { applicants } \\
\text { autumn } \\
2008\end{array}$ \\
\hline \multirow{5}{*}{$\begin{array}{l}\text { Socio- } \\
\text { economic } \\
\text { back- } \\
\text { ground }\end{array}$} & SEI 1 & 7.4 & 12.5 & 10.1 & 25.0 & 31.2 & 27.0 \\
\hline & SEI 2 & 41.0 & 32.6 & 36.6 & 44.9 & 41.9 & 43.5 \\
\hline & SEI 3 & 43.0 & 45.1 & 44.1 & 19.6 & 16.4 & 18.3 \\
\hline & Not indexed & 8.6 & 9.8 & 9.2 & 10.5 & 10.6 & 11.2 \\
\hline & $\begin{array}{l}\text { Total } \\
\text { Total (N) }\end{array}$ & $\begin{array}{r}100.0 \\
2157684\end{array}$ & $\begin{array}{r}100.0 \\
2333809\end{array}$ & $\begin{array}{r}100.0 \\
4491493\end{array}$ & $\begin{array}{r}100.0 \\
183426\end{array}$ & $\begin{array}{r}100.0 \\
103189\end{array}$ & $\begin{array}{r}100.0 \\
288986\end{array}$ \\
\hline
\end{tabular}

As described above, there are a number of different types of eligibility, and a single applicant can register based on more than one type of eligibility. The dominant group is those with eligibility based on upper secondary school grades (77.4\%). Of the applicants, $2.7 \%$, or 7,682 applicants, have only 25:4 eligibility. However, a large number $(10.6 \%)$ have more than one type of eligibility, including another $9.1 \%(26,225)$ who also have 25:4 eligibility. Finally, $4.3 \%$ have their only eligibility from formal adult education or a folk high school (table 5). 
Table 5. Different types of basic eligibility among applicants

\begin{tabular}{lrr}
\hline Type of eligibility & \multicolumn{2}{c}{$\%$} \\
\hline Upsec & 223794 & 77.4 \\
AE & 8684 & 3.0 \\
FHS & 3758 & 1.3 \\
Foreign & 9516 & 3.3 \\
$25: 4$ & 7682 & 2.7 \\
Other & 5113 & 1.8 \\
$25: 4+$ Upsec & 23373 & 8.1 \\
$25: 4+$ more, not Upsec & 2852 & 1.0 \\
More than one, not 25:4 & 4214 & 1.5 \\
\hline Total & 288986 & 100.0 \\
\hline
\end{tabular}

It should be noted that the eligibility registered at VHS is based on the submitted applications. A comparison with the actual educational backgrounds registered at Statistics Sweden shows that 1,332 of the 7,682 applicants with only 25:4 eligibility had actually taken a programme in upper secondary school; however, they did not necessarily take a programme that provided basic eligibility. An estimation based on the type of upper secondary education registered is that 714 members of the 25:4 group had taken a programme that could have provided basic eligibility.

These different background variables have been related to the varying types of eligibility. This analysis shows that there are more men than expected among those with only upper secondary school or formal adult education eligibility, while there are more women in all the other groups (table 6). 
Table 6. Distribution of female and male applicants of different types of eligibility: autumn 2008

\begin{tabular}{llrrr}
\hline & & \multicolumn{2}{c}{ Gender (\%) } & \\
\cline { 3 - 4 } Eligibility & Female & Male & N \\
& Upsec & 62.0 & 38.0 & 223545 \\
& AE & 61.7 & 38.3 & 8658 \\
& FHS & $(64.7)$ & $(35.3)$ & 3737 \\
& Foreign & 71.3 & 28.7 & 7617 \\
& 25:4 & 70.4 & 29.6 & 7640 \\
& Other & 69.3 & 30.7 & 5070 \\
& $25: 4+$ Upsec & 75.3 & 24.7 & 23343 \\
& $25: 4+$ more, not Upsec & 76.5 & 23.5 & 2809 \\
& More than one, not 25:4 & 72.1 & 27.9 & 4196 \\
\hline \multirow{2}{*}{ Total } & & 64.0 & 36.0 & 286615 \\
\hline
\end{tabular}

Note: Internal drop-out $0.8 \%$

Further, concerning socioeconomic background, the results show that more nontraditional applicants - including those with eligibility from formal adult education, folk high school, 25:4, or 25:4 combined with some type of eligibility other than upper secondary school - have a working-class background than in the other groups of applicants (table 7). It should be noted that the socioeconomic backgrounds of a rather high number of the applicants are not indexed. However, as shown above (table 4), the proportion of non-indexed people is almost as high in the comparable population. We can also see (table 7) that the index is particularly thin in the group with foreign eligibility - it could be expected that a high number of people in this group were not living in Sweden when the index was made. 
Table 7. Socioeconomic backgrounds of applicants with different types of eligibility

\begin{tabular}{llrrrrr}
\hline & \multicolumn{3}{c}{ Socioeconomic background (\%) } & \multirow{2}{*}{$N$} \\
\cline { 3 - 6 } & & SOC I & SOC II & SOC III & Not indexed & \multirow{2}{*}{ SOC. } \\
\hline \multirow{2}{*}{ Eligibility } & Upsec & 28.8 & 44.6 & 18.6 & 8.0 & 223794 \\
& AE & 19.1 & 35.8 & 22.6 & 22.5 & 8684 \\
& FHS & 19.3 & 38.9 & 22.4 & 19.5 & 3758 \\
& Foreign & 10.6 & 9.8 & 3.8 & 75.7 & 9516 \\
& $25: 4$ & 16.9 & 42.0 & 22.9 & 18.2 & 7682 \\
& Other & $(26.6)$ & 41.2 & 14.5 & 17.7 & 5113 \\
& $25: 4+$ Upsec & $(26.7)$ & 52.8 & $(18.0)$ & 2.5 & 23373 \\
& $25: 4+$ more, not Upsec & 10.9 & 30.5 & 20.3 & 38.3 & 2852 \\
& More than one, not 25:4 & 24.8 & $(42.8)$ & $(17.8)$ & 14.6 & 4214 \\
\hline \multirow{2}{*}{ Total } & 27.0 & 43.5 & 18.3 & 11.2 & 288986 \\
\hline
\end{tabular}

We can also see that applicants with a foreign background have attended Swedish upper secondary school to a lower degree than those with a Swedish background; in this sense, these applicants could be viewed as non-traditional (table 8). This probably reflects the fact that many of them came to Sweden as adults. Nevertheless, upper secondary school is the most common type of eligibility, even among those with a foreign background.

Table 8. Swedish/foreign backgrounds of applicants with different types of eligibility

\begin{tabular}{|c|c|c|c|c|}
\hline & & \multicolumn{2}{|c|}{ Swedish/Foreign background (\%) } & \multirow[b]{2}{*}{$N$} \\
\hline & & Swedish & Foreign & \\
\hline \multirow[t]{8}{*}{ Eligibility } & $\begin{array}{l}\text { Upsec } \\
A E\end{array}$ & $\begin{array}{l}87.2 \\
70.9\end{array}$ & $\begin{array}{l}12.8 \\
29.1\end{array}$ & $\begin{array}{r}222258 \\
8622\end{array}$ \\
\hline & FHS & 75.8 & 24.2 & 3723 \\
\hline & Foreign & 23.7 & 76.3 & 7488 \\
\hline & $25: 4$ & 72.3 & 27.7 & 7602 \\
\hline & Other & 75.0 & 25.0 & 5023 \\
\hline & $25: 4+$ Upsec & 92.5 & 7.5 & 23182 \\
\hline & 25:4 + more, not Upsec & 50.7 & 49.3 & 2800 \\
\hline & More than one, not $25: 4$ & 79.9 & 20.1 & 4175 \\
\hline Total & & 84.2 & 15.8 & 284873 \\
\hline
\end{tabular}

Note: Internal drop-out 1.4\% 
When we consider the way applicants with varying types of eligibility are distributed in the different age groups (table 9), we can see that 'non-traditional' types of eligibility, i.e. not upper secondary school, are more common in the non-traditional age group of 25+. This is inevitably the case for the 25:4 eligibility group, which requires an age of 25 . However, it is particularly notable that eligibility from formal adult education or folk high school is more common in the age group 25-34, while 25:4 eligibility is more common in the age group 35-44.

Table 9. Distribution of age groups of applicants with different types of eligibility

\begin{tabular}{|c|c|c|c|c|c|c|c|c|}
\hline & & \multicolumn{6}{|c|}{ Age group (\%) } & \multirow[b]{2}{*}{$N$} \\
\hline & & $16-24$ & $25-34$ & $35-44$ & $45-54$ & $55-64$ & $65+$ & \\
\hline \multirow[t]{8}{*}{ Eligibility } & $\begin{array}{l}\text { Upsec } \\
A E\end{array}$ & $\begin{array}{l}59.4 \\
26.1\end{array}$ & $\begin{array}{l}28.0 \\
52.1\end{array}$ & $\begin{array}{r}8.1 \\
14.6\end{array}$ & $\begin{array}{r}3.3 \\
(6.3)\end{array}$ & $\begin{array}{l}1.0 \\
0.8\end{array}$ & $\begin{array}{l}0.3 \\
0.1\end{array}$ & $\begin{array}{r}223545 \\
8658\end{array}$ \\
\hline & FHS & 30.0 & 47.5 & (14.3) & (6.5) & $(1.5)$ & 0.2 & 3737 \\
\hline & Foreign & 39.2 & 38.5 & 16.9 & 4.5 & 0.7 & 0.1 & 7617 \\
\hline & $25: 4$ & 0.0 ** & 23.2 & 39.0 & 27.4 & 7.8 & 2.6 & 7640 \\
\hline & Other & 1.6 & 30.9 & 34.7 & 23.0 & 8.4 & 1.5 & 5070 \\
\hline & $25: 4+$ Upsec & 0.0 * & 28.5 & 47.8 & 18.9 & 3.9 & 0.9 & 23343 \\
\hline & $25: 4+$ more, not Upsec & 0.0 * & 23.5 & 48.3 & 24.2 & 3.5 & $(0.5)$ & 2809 \\
\hline & More than one, not $25: 4$ & 23.0 & 45.8 & 22.0 & 7.3 & $(1.5)$ & $(0.5)$ & 4196 \\
\hline Total & & 48.9 & 29.4 & 13.7 & 6.0 & 1.6 & 0.4 & 286615 \\
\hline
\end{tabular}

${ }^{*} \mathrm{~N}=0{ }^{* \star} \mathrm{N}=1$

Note: Internal drop-out $0.8 \%$

\section{Applications for autumn 2008}

We will now focus on the actual applications for higher education in the group described above. First, it should be noted that the applications allow each individual to apply for a number of ranked alternatives. In the present analysis of the contents of the applications, the focus is on the first priority among the applicants' alternatives.

When we look more closely at the admission round of autumn 2008 and the applicants' first priorities, the initial focus is on what type of institution the applicants wish to attend (table 10). The distribution of choices is quite similar between the eligibility groups. However, it is evident that applicants with only upper secondary 
school or foreign eligibility apply to courses/programmes in universities and prestigious institutes to a higher degree and to courses/programmes in university colleges to a lower degree than the other groups of applicants. Applicants with eligibility through 25:4 or from formal adult education, folk high school, or 'other pre-education' exhibit the opposite tendency as compared to the total distribution.

Table 10. Type of institution applied to (distribution in \%) in different eligibility groups

\begin{tabular}{llrrrr}
\hline & & \multicolumn{3}{c}{ Type of institution } \\
\cline { 3 - 5 } & & University & Institute & $\begin{array}{c}\text { University } \\
\text { college }\end{array}$ & $N$ \\
\hline \multirow{2}{*}{ Eligibility } & Upsec & 64.4 & 7.3 & 28.3 & 223794 \\
& AE & 59.7 & $(6.5)$ & 33.7 & 8684 \\
& FHS & $(62.4)$ & 3.6 & 34.0 & 3758 \\
& Foreign & 65.1 & 11.1 & 23.9 & 9516 \\
& $25: 4$ & 59.8 & 3.8 & 36.4 & 7682 \\
& Other & 61.2 & 3.2 & 35.6 & 5113 \\
& $25: 4+$ Upsec & 60.8 & 3.3 & 35.9 & 23373 \\
& $25: 4+$ more, not Upsec & 59.0 & $(6.3)$ & 34.7 & 2852 \\
& More than one, not $25: 4$ & $(62.4)$ & 5.1 & 32.5 & 4214 \\
\hline \multirow{2}{*}{ Total } & & 63.7 & 6.8 & 29.5 & 288986 \\
\hline
\end{tabular}

If we consider the length of the course being applied to in terms of its credit points, we observe additional interesting differences (table 11). Those with only 25:4 eligibility or 25:4 combined with upper secondary school applied to short courses (maximum 15 credit points) to a higher extent than all the other groups but one: those with 'other preeducation'. As the main type of 'other pre-education' is eligibility based on prior course studies at university level, this probably means that the group in question mainly consists of 'course students'. Other non-traditional groups do not exhibit this pattern. 
Table 11. Length of course/programme applied to (distribution in \%) in different eligibility groups

\begin{tabular}{|c|c|c|c|c|c|c|c|}
\hline & & \multicolumn{5}{|c|}{ Credit points } & \multirow[b]{2}{*}{$\mathrm{N}$} \\
\hline & & $0-15$ & $16-30$ & $31-60$ & $61-180$ & $181-330$ & \\
\hline \multirow[t]{8}{*}{ Eligibility } & $\begin{array}{l}\text { Upsec } \\
A E\end{array}$ & $\begin{array}{l}33.3 \\
30.1\end{array}$ & $\begin{array}{l}20.2 \\
21.8\end{array}$ & $\begin{array}{r}4.1 \\
(4.0)\end{array}$ & $\begin{array}{l}23.8 \\
26.6\end{array}$ & $\begin{array}{r}18.6 \\
(17.6)\end{array}$ & $\begin{array}{r}218599 \\
8501\end{array}$ \\
\hline & FHS & 26.6 & 23.1 & $(4.9)$ & 23.9 & 21.5 & 3693 \\
\hline & Foreign & 26.4 & $(21.1)$ & (4.4) & 28.6 & 19.4 & 9263 \\
\hline & $25: 4$ & 44.9 & 26.0 & 4.9 & 15.7 & 8.5 & 7542 \\
\hline & Other & 61.0 & (20.3) & 6.9 & 10.4 & 1.4 & 5029 \\
\hline & $25: 4+$ Upsec & 52.2 & 24.1 & 5.2 & 12.1 & 6.4 & 22929 \\
\hline & $25: 4+$ more, not Upsec & 38.8 & 23.8 & 5.3 & 19.6 & 12.5 & 2799 \\
\hline & More than one, not $25: 4$ & $(36.2)$ & $(20.4)$ & $(4.5)$ & 19.0 & 19.9 & 4107 \\
\hline Total & & 35.3 & 20.8 & 4.3 & 22.5 & 17.0 & 282462 \\
\hline
\end{tabular}

Note: Internal drop-out 2.3\%

An analysis of eligibility in relation to the courses' study pace (table 12) demonstrates that the groups that choose short courses to a higher degree also are those who applied to courses with a low study pace of a maximum of $25 \%$ of full-time study. That is, these groups apply for short courses with a low study pace to a higher extent than other applicants.

Another indicator of the type of studies applied for is the form of instruction either 'normal' (on campus) or 'distance' studies (table 13). In this area, the distinctive choices of the 25:4, other pre-education, and 25:4 combined with upper secondary school groups also stand out. The difference is that these groups apply for distance courses to a higher extent than other eligibility groups. Furthermore, it should be noted that the group of applicants with 25:4 combined with something other than upper secondary school also has a comparatively high degree of applications to distance courses. 
Table 12. Study pace in courses/programmes applied to (distribution in \%) in different eligibility groups

\begin{tabular}{llrrrr}
\hline & & \multicolumn{3}{c}{ Study pace } & \\
\cline { 3 - 5 } & & $1-25 \%$ & $26-50 \%$ & $51-100 \%$ & \multirow{2}{*}{$N$} \\
\hline \multirow{2}{*}{ Eligibility } & Upsec & 7.9 & 23.5 & 68.6 & 223794 \\
& AE & 7.0 & 22.8 & 70.1 & 8684 \\
& FHS & 6.4 & 21.2 & 72.5 & 3758 \\
& Foreign & 4.9 & 19.6 & 75.5 & 9516 \\
& 25:4 & 13.3 & 41.1 & 45.6 & 7682 \\
& Other & 25.2 & 50.9 & 23.9 & 5113 \\
& $25: 4+$ Upsec & 14.7 & 46.2 & 39.1 & 23373 \\
& $25: 4+$ more, not Upsec & $(8.9)$ & 36.3 & 54.8 & 2852 \\
& More than one, not 25:4 & 10.8 & 30.3 & 58.9 & 4214 \\
\hline \multirow{2}{*}{ Total } & & 8.8 & 26.3 & 64.8 & 288986
\end{tabular}

Note: Most courses with a higher study pace than $50 \%$ are full-time courses (study pace $100 \%$ )

Table 13. Teaching forms of course/programmes applied to (distribution in \%) in different eligibility groups

\begin{tabular}{llrrr}
\hline & & \multicolumn{2}{c}{ Teaching form } & \\
\cline { 3 - 4 } & & Normal & Distance & $N$ \\
\hline \multirow{2}{*}{ Eligibility } & Upsec & 89.8 & 10.2 & 197734 \\
& AE & $(88.0)$ & $(12.0)$ & 7557 \\
& FHS & 89.3 & 10.7 & 3286 \\
& Foreign & 91.4 & 8.6 & 8590 \\
& 25:4 & 75.2 & 24.8 & 5995 \\
& Other & 70.2 & 29.8 & 3775 \\
& $25: 4+$ Upsec & 72.9 & 27.1 & 18005 \\
& $25: 4+$ more, not Upsec & 77.6 & 22.4 & 2330 \\
& More than one, not 25:4 & 84.1 & 15.9 & 3489 \\
\hline \multirow{2}{*}{ Total } & & 87.7 & 12.3 & 250761 \\
\hline
\end{tabular}

Note: Internal drop-out $13.2 \%$

Furthermore, the data include the results of the admission process; in this study, the focus is on the results concerning the applicants' first-priority choice. The data show that those with 25:4 eligibility, and particularly those with 25:4 combined with upper secondary school, are admitted to a higher extent than the other eligibility groups (table 14). Based on the results concerning course length, study pace, and form of instruction, a 
reasonable explanation for this result is that these groups apply for courses to which it is relatively easy to be admitted, as compared to groups that prefer longer courses/programmes and a higher study pace. However, these differences are not very great.

We can also observe how the result of the admission process relates to certain additional background factors. There are only minor differences when it comes to social background, at least among those with a registered socioeconomic background (table 14). However, the admission rate is notably lower among those not indexed.

Table 14. Results of selection process (distribution in \%) in different eligibility groups, and for applicants with different socioeconomic background

\begin{tabular}{|c|c|c|c|c|c|}
\hline & & \multicolumn{3}{|c|}{ Result } & \multirow[b]{2}{*}{$N$} \\
\hline & & Admitted & Substitute & Rejected & \\
\hline \multirow[t]{9}{*}{ Eligibility } & Upsec & 51.0 & (11.2) & (37.7) & 223794 \\
\hline & $A E$ & 48.8 & 12.1 & 39.1 & 8684 \\
\hline & FHS & 43.8 & 15.6 & 40.6 & 3758 \\
\hline & Foreign & 48.1 & 10.3 & 41.6 & 9516 \\
\hline & $25: 4$ & 52.9 & 10.1 & $(37.0)$ & 7682 \\
\hline & Other & $(50.4)$ & 6.6 & 43.1 & 5113 \\
\hline & $25: 4+$ Upsec & 58.4 & 8.6 & 32.9 & 23373 \\
\hline & 25:4 + more, not Upsec & $(50.8)$ & 14.6 & 34.6 & 2852 \\
\hline & More than one, not $25: 4$ & 48.3 & 15.1 & $(36.6)$ & 4214 \\
\hline \multirow{4}{*}{$\begin{array}{l}\text { Socioeconomic } \\
\text { background }\end{array}$} & SOC I & 52.9 & 10.2 & 36.9 & 78027 \\
\hline & SOC II & 52.2 & 10.3 & $(37.6)$ & 125652 \\
\hline & SOC III & $(51.0)$ & 11.8 & (37.3) & 52872 \\
\hline & Not indexed & 45.0 & 15.2 & 39.9 & 32435 \\
\hline Total & & 51.4 & 11.1 & 37.6 & 288986 \\
\hline
\end{tabular}

Further, those with a foreign background are admitted to a somewhat lower extent than applicants with a Swedish background (table 15). As we have seen (table 7), those with a foreign educational background are indexed to a lower extent, and a closer look at the data concerning socioeconomic background shows that foreign background and a missing socioeconomic indexing are strongly related. Among those with a registered 
Swedish/foreign background, a socioeconomic index is missing for $10.5 \%$ or 30,052 of the applicants, and $88.2 \%$ of those applicants have a foreign background.

Table 15. Results of selection process (distribution in \%) for applicants with foreign/Swedish backgrounds

\begin{tabular}{|c|c|c|c|c|c|}
\hline & & \multicolumn{3}{|c|}{ Result } & \multirow[b]{2}{*}{$N$} \\
\hline & & Admitted & Substitute & Rejected & \\
\hline Foreign/ & Foreign background & 45.7 & 15.8 & 38.5 & 44877 \\
\hline Swedish & Swedish background & 52.6 & 10.2 & 37.2 & 239996 \\
\hline Total & & 51.5 & 11.1 & 37.4 & 284873 \\
\hline
\end{tabular}

Note. Internal drop-out $1.4 \%$.

The gender differences are also small, but men are admitted to a slightly higher extent than women (table 16). On the other hand, the results of the different age groups (table 16) exhibit an interesting pattern. The admission rate is higher for older students than for younger students. This is most likely also related to the types of courses to which the different age groups apply.

Table 16. Results of selection process (distribution in \%) for female and male applicants, and in different age groups

\begin{tabular}{llrrrr}
\hline & & \multicolumn{3}{c}{ Result } & \multirow{2}{*}{ Rejected } \\
\cline { 3 - 5 } & & Admitted & Substitute & Rer & 183426 \\
\hline Gender & Female & 50.9 & 11.9 & $(37.3)$ & 103189 \\
& Male & 52.5 & 9.7 & 37.8 & 140201 \\
\hline Age & $16-24$ & 49.4 & 13.3 & $(37.3)$ & 84288 \\
group & $25-34$ & 52.1 & 9.6 & 38.3 & 39276 \\
& $35-44$ & 53.6 & 8.7 & $(37.8)$ & 17162 \\
& $45-54$ & 56.8 & 6.9 & 36.3 & 4508 \\
& $55-64$ & 60.9 & 5.7 & 33.5 & 1180 \\
\hline \multirow{2}{*}{ Total } & $65+$ & 72.1 & 4.8 & 23.1 & 286615 \\
\hline
\end{tabular}

Note: Internal drop-out $0.8 \%$

Thus, the general pattern is that older applicants with 25:4 eligibility apply for shorter, part-time, distance courses, and courses at university colleges to a higher extent than 
most other groups; they are also admitted to a slightly higher extent. This will be discussed in the concluding section of the article.

\section{Concluding discussion}

We can see that a majority of the applicants to higher education are non-traditional in the sense that they are 25+ in age. Furthermore, it is not only the pool of applicants that exhibits a high proportion of more or fewer older people. The data show that the admission rate is higher for older students than for younger. Even if this is related to the type of courses that different age groups apply for, it also indicates that there is a high number of older students. The present study focuses on the choice to apply for higher education and does not include an analysis of the extent to which the applicants in this 'cohort' actually enter higher education and whether they continue to study or drop out. However, it is a fact (see table 3 ) that $55 \%$ of all students in Swedish higher education in autumn 2008 were 25+. Nevertheless, the complexity of higher education must be considered to permit a discussion of the outcome of the selection process and the associated 'risk' that younger students will not be admitted in favour of older candidates. The results presented here indicate that the older applicants are, to a high degree, interested in shorter, part-time courses, which means that they do not 'fill up' the longer programmes in a way that eliminates the opportunities available to younger students.

There is a high number of applicants who are non-traditional in terms of age. Nevertheless, it should be noted that the traditional background in upper secondary school is by far the most common type of basic eligibility. That said, it is still a fact that basic eligibility based on the 25:4 scheme is the most common non-traditional category. One out of six applicants has 25:4 eligibility, even if in most cases it is combined with some other type of eligibility. Concerning the different types of non-traditional 
eligibility, it should be noted that the eligibility from formal adult education and from folk high school is more common in the age group 25-34, while 25:4 eligibility is more common in the age group 35-44. Among the applicants with 25:4 eligibility, there are also more women than expected. The fact that 25:4 eligibility is more common among older applicants $(35+)$ could indicate that the consequences of removing the scheme as a second chance decrease over time. However, a complementary conclusion is that employees' opportunities for competence development through higher education are reduced.

When it comes to the differences within the non-traditional (25+) age group mentioned in the previous paragraph, it would be interesting to analyse the relations between age, eligibility, and varying opportunity structures in the Swedish educational system. Could the reforms to this system at certain points in the structural development of higher education help explain the variations between age groups? However, this is a topic for another study.

When we consider the applicants' socioeconomic backgrounds, this study indicates that to a higher extent applicants with a non-traditional type of eligibility have working-class backgrounds. Thus, it appears that these eligibility groups compensate, to an extent, for the under-representation of applicants with working-class backgrounds. However, in the rate of admission the differences are small and only slightly in favour of those with a middle-class background; no significant influence can be observed for socioeconomic background. The conclusion is that the opportunity to apply with a nontraditional eligibility/background stimulates the choice to submit an application among those with a lower socioeconomic status. However, this does not mean that they are successful in the admission process. 
Analysing the programme and course choices in the applications and focusing on the applicants' first priorities, we can observe that 25:4 applicants in particular, and other non-traditional applicants to some degree, apply to university colleges rather than universities. Further, those with only $25: 4$ or 25:4 combined with upper secondary school eligibility applied to short courses (maximum 15 credit points) to a higher extent than all other groups but one - those with 'other pre-education' - while other nontraditional groups do not exhibit this pattern. In fact, these groups apply for short courses with a low study pace and distance courses to a higher extent than the other applicants. In relation to this pattern, those with 25:4 or 25:4 combined with upper secondary school eligibility are admitted to a higher extent than those in other eligibility groups. Based on the data on course length, study pace, and teaching form, a reasonable explanation for this result could be that these groups apply for courses to which it is relatively easy to be admitted, compared to groups that prefer longer courses/programmes and a higher study pace. However, the relation between the type of courses applied for and opportunities for admission should not be interpreted by assuming that non-traditional applicants apply for these courses because it is easier to gain admission to them. The reasons for this choice should, rather, be sought in the opportunity structures of their personal life situations, where family, work, economic situation, etc., could be important factors. Taking a short, part-time course is likely easier to combine with work and family life than more extensive alternatives, and distance courses and courses at university colleges are generally easier to take 'from home' than on-campus and university courses. The latter conclusion is, of course, related to the geographical situation, with few universities - most of them being located in the bigger Swedish cities - and more university colleges spread out in medium-sized cities around the country. 
Further, it should be pointed out that according to the results of the analysis presented here, the 25:4 initiative has actually been successful, in that it has fulfilled the expectations set out at the introduction of the idea and the scheme. The 25:4s were admitted to their courses and programmes of choice to a higher degree than other types of applicants, and the characteristics of the group indicate that this has contributed to the widening of access to higher education in Sweden. Furthermore, in terms of length, study pace, and teaching form, the types of courses these candidates applied to also indicates success in terms of providing opportunities for competence development for employees - shorter distance courses with a lower study pace are more likely to be combined with work.

In summary, according to the present study, one cannot say whether the system of basic eligibility is a general threshold on the way into higher education or not, as the focus population consists of applicants who already have this eligibility. However, the results indicate that the presence of different types of eligibility reduces the threshold and widens access to higher education. Therefore, it could be argued that the removal of the 25:4 scheme may mean that a threshold will be introduced for some people. We may also observe that basic eligibility appears to act as - or, rather, interact with - other factors as a fork in the road of the application and selection process. There are clear differences between the groups with different types of eligibility, which demonstrate that the varying backgrounds of the different eligibility groups have an influence on their choices of courses/programmes in higher education.

\section{References}

Andersson, P. and Fejes, A. (2005) 'Recognition of prior learning as a technique for fabricating the adult learner: a genealogical analysis on Swedish adult education policy', Journal of Education Policy, vol 20(5), pp. 595-613. 
Berggren, C. (2006) Entering Higher Education - Gender and Class Perspectives,

Göteborg: Acta Universitatis Gothoburgensis, Göteborg Studies in Educational Sciences, 243.

Cliffordson, C. and Askling, B. (2006) 'Different grounds for admission: its effects on recruitment and achievement in medical education', Scandinavian Journal of Educational Research, vol 50(1), pp. 45-62.

Davies, P. (ed.) (1995) Adults in Higher Education. International Perspectives in Access and Participation, Bristol: Jessica Kingsley.

Kim, L. (1982) Widened Admission to Higher Education in Sweden: The 25/5 Scheme. A study of the implementation process, Stockholm: National Board of Universities and Colleges.

Kim, L. (1983) Att välja eller väljas: En studie av tillträdesreglerna och övergången från gymnasieskola till högskola [To choose or to be chosen: A study of the admission rules and the transition from upper secondary school to higher education; in Swedish], Forskning och Utveckling för högskolan, Projektrapport 1983:4, Stockholm: Universitets- och Högskoleämbetet.

Kim, L. (1998) Val och urval till högre utbildning: En studie baserad på erfarenheterna av 1977 års tillträdesreform [Choice and selection in higher education: A study based on the experiences of the 1977 admissions reform in Sweden; in Swedish], Uppsala Studies in Education 76, Uppsala: Acta Universitatis Upsaliensis.

Mark, R., Pouget, M. and Thomas, E. (eds) (2006) Adults in Higher Education. Learning from Experience in the New Europe (2nd edition), Bern: Peter Lang. Ministry of Education (1970) Vägar till högre utbildning. Behörighet och urval [Tracks to higher education: Eligibility and selection; in Swedish], SOU 1970:21, Stockholm: Utbildningsdepartementet. 
Ministry of Education (1974) Om behörighet och antagning till högskolan [On eligibility and admission to higher education; in Swedish], SOU 1974:71, Stockholm: Utbildningsdepartementet.

Osborne, M. (2003) ‘Increasing or widening participation in higher education? - a European overview', European Journal of Education, vol 38(1), pp. 5-24.

Stage, C. (1988) 'Gender differences in test results', Scandinavian Journal of Educational Research, vol 32(3), pp. 101-111.

Stage, C. (1993) Gender Differences on the SweSAT. A review of studies since 1975, Em No 7, Umeå: Umeå university, Department of Educational Measurement.

Stage, C. (2005) Socialgruppsskillnader i resultat på högskoleprovet [Socioeconomic group differences in the result on SweSAT; in Swedish], BVM nr 11, 2005, Umeå: Umeå Universitet.

Statistics Sweden (2010) Official statistics, available online at www.scb.se (accessed 2 November 2010).

Wedman, I. (1994) 'The Swedish Scholastic Aptitude Test: Development, use, and research', Educational Measurement: Issues and Practice, vol 13(2), pp. 5-11. 